\section{Fermentative bacteria from estuarine mud: phylogenetic position of Acidaminobacter hydrogenoformans and description of a new type of Gram-negative, propionigenic bacterium as Propionibacter pelophilus gen. nov., sp. nov.}

\author{
Wim G. Meijer, ${ }^{1,2}$ Manny E. Nienhuis-Kuiper ${ }^{1}$ and Theo A. Hansen ${ }^{1}$
}

\footnotetext{
1 Department of

Microbiology, Groningen Biomolecular Sciences and Biotechnology Institute, University of Groningen, Kerklaan 30, NL-9751 NN Haren, The Netherlands

2 Department of Industrial Microbiology, University College Dublin, Dublin 4, Ireland
}

\author{
Author for correspondence: Theo A. Hansen. Tel: +31 503632163 . Fax: + 31503632154. \\ e-mail: hansenta@biol.rug.nl
}

\begin{abstract}
The phylogenetic positions of two strains of fermentative bacteria that had been isolated from the highest positive tubes inoculated with serial dilutions of estuarine mud in agar media with either glutamate or aspartate as substrate were determined by comparative sequence analysis of their $16 \mathrm{~S}$ rRNA genes. The strain isolated with glutamate (glu 65) utilized several substrates, including a number of amino acids but no sugars. The degradation of certain substrates was enhanced by or dependent upon co-cultivation with a hydrogen-utilizing partner. In earlier work this strain was assigned to the new genus and species Acidaminobacter hydrogenoformans. On the basis of its 165 rRNA gene sequence Acidaminobacter hydrogenoformans has now been identified as a member of cluster XI of the Clostridium subphylum with Clostridium halophilum as its closest relative. The aspartate-fermenting strain asp $66^{\top}$ was a Gram-negative, rather aerotolerant anaerobe which utilized a wide range of substrates in a propionic fermentation and had the ability to fix molecular nitrogen. Strain asp $66^{\top}$ was shown to be a new member of the $\beta$ subclass of the Proteobacteria with Azoarcus sp. strain 6 a3 and Rhodocyclus tenuis as its closest relatives. It is described as Propionibacter pelophilus gen. nov., sp. nov., with the type strain asp $6^{\top}$ (= DSM 12018').
\end{abstract}

Keywords: Propionibacter gen. nov., Acidaminobacter, propionic fermentation

\section{INTRODUCTION}

In 1982 in the laboratory of one of us two new types of fermentative bacteria were isolated from mud of the Ems-Dollard estuary at the border between Germany and The Netherlands. These rod-shaped bacteria were obtained from the highest positive dilutions in anoxic agar media with glutamate or aspartate as the substrate. The glutamate-fermenting strain (glu 65) stained Gram-negative; electron micrographs, however, showed that it did not have a typically Gramnegative cell envelope. It fermented several substrates but some of them were only utilized in co-cultures with

The GenBank accession numbers for the 165 rRNA gene sequences of Propionibacter pelophilus and Acidaminobacter hydrogenoformans are AF016690 and AF016691, respectively. a hydrogenotrophic partner. Furthermore, in cocultures the fermentation of glutamate was faster and it was shifted towards the conversion of glutamate to propionate, $\mathrm{CO}_{2}$ and hydrogen. This strain was described as the type strain of Acidaminobacter hydrogenoformans gen. nov., sp. nov. (Stams \& Hansen, 1984). The aspartate-fermenting strain asp $66^{\mathrm{T}}$ was Gram-negative; in addition to aspartate, it fermented several substrates (sugars, sugar alcohols, dicarboxylic acids) in a propionic fermentation. It grew in mineral media with a single substrate, could fix $\mathrm{N}_{2}$, and was rather oxygen-tolerant but did not grow in wellaerated cultures (Hansen et al., 1990). It was speculated that despite its use of a much larger diversity of substrates strain asp $66^{\mathrm{T}}$ might be related to Pelobacter propionicus, which is now known to belong to the $\delta$ subclass of the Proteobacteria (Evers et al., 1993) but 
whose phylogenetic position was unknown when strain asp $66^{\mathrm{T}}$ was characterized.

In this paper we describe the phylogenetic position of strain asp $66^{\mathrm{T}}$, show that it belongs to the $\beta$-subclass of the Proteobacteria and describe it as the type strain of a new genus and species for which we propose the name Propionibacter pelophilus gen. nov., sp. nov. We also show that on the basis of the 16S rRNA gene sequence Acidaminobacter hydrogenoformans groups with Gram-positive anaerobes belonging to cluster XI of the Clostridium subphylum.

\section{METHODS}

Cultivation of the strains. Strain asp $66^{\mathrm{T}}\left(\mathrm{DSMZ} 12018^{\mathrm{T}}\right)$ was grown in minimal bicarbonate-buffered media with aspartate or glucose as carbon and energy source as described previously (Hansen et al., 1990). Acidaminobacter hydrogenoformans (DSMZ 2784 ${ }^{\mathrm{T}}$ ) was grown in a medium with $20 \mathrm{mM}$ glutamate as described (Stams \& Hansen, 1984). Culture purity and identity were verified by phasecontrast microscopy and analysis of the fermentation products.

Comparative sequence analysis of 165 rRNA genes. Chromosomal DNA was isolated as described previously (Van der Maarel et al., 1996). The 16S rRNA genes were amplified by PCR using Pwo DNA polymerase as recommended by the manufacturer (Boehringer) using the oligonucleotides $5^{\prime}$ ACCTAATACGACTACTATAGGGAGAGTTTGATCCTGGCTCAG $3^{\prime}$ and 5' ATTGTAAAACGACGGCCAGTGGTTACCTTGTTACGACTT $3^{\prime}$. The $3^{\prime}$ ends of these primers are complementary to conserved rRNA sequences corresponding to positions 8-27 and 1492-1510, respectively, of the Escherichia coli rRNA gene; the 5' ends of these primers are complementary to two universal fluorescently labelled sequencing primers. The reaction mixture was pre-incubated at $95^{\circ} \mathrm{C}$ for $5 \mathrm{~min}$ and subsequently subjected to 27 cycles of $94{ }^{\circ} \mathrm{C}$ for $45 \mathrm{~s}, 52^{\circ} \mathrm{C}$ for $45 \mathrm{~s}, 72^{\circ} \mathrm{C}$ for $120 \mathrm{~s}$ followed by an incubation at $72^{\circ} \mathrm{C}$ for $7 \mathrm{~min}$. The PCR product was purified using Qiaquick spin columns (Qiagen). The nucleotide sequence of the amplified 16S rRNA genes was determined using an ALF Express DNA sequencer (Pharmacia) using ThermoSequenase as recommended by the manufacturer (Amersham). The nucleotide sequences were compared to entries in the database at the National Center for Biotechnology Information using the program BLASTN (Altschul et al., 1990). The phylogeny of the sequences was analysed by parsimony using the program DNAPARS of the PHYLIP 3.5c package (Felsenstein, 1995) and by calculating a distance matrix according to the twoparameter model of Kimura (1980) followed by the construction of a phylogenetic tree using the neighbour-joining method (Saitou \& Nei, 1987) as implemented in the program TREECON (Van de Peer \& De Wachter, 1995).

\section{RESULTS}

\section{Acidaminobacter hydrogenoformans belongs to clostridial cluster $\mathbf{X I}$}

Although Acidaminobacter hydrogenoformans stains Gram-negative, its ultrastructure suggests that it belongs to the Gram-positive bacteria (Stams \& Hansen, 1984). In order to clarify the phylogenetic

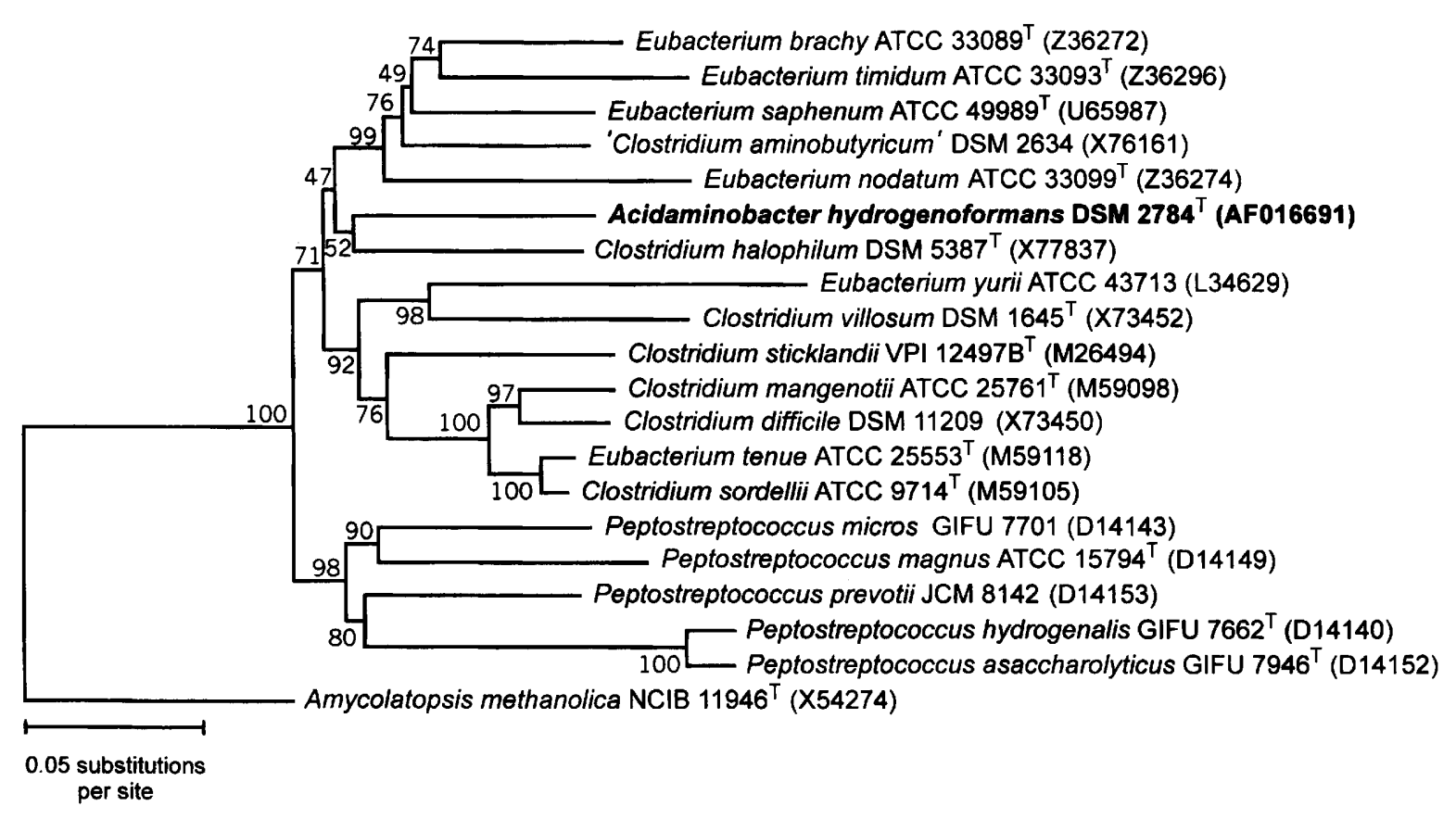

Fig. 1. Phylogenetic relationships of strain glu 65 (Acidaminobacter hydrogenoformans) with species belonging to the low-G $+C$ Gram-positive bacteria. The phylogenetic tree is based on a distance matrix of 165 rRNA sequences and was constructed using the neighbour-joining method. Amycolatopsis methanolica was used as an outgroup. Bootstrap values (percentage) are based on 500 replicates and are given at each node. The accession numbers of the sequences of the reference strains are given in parentheses. 


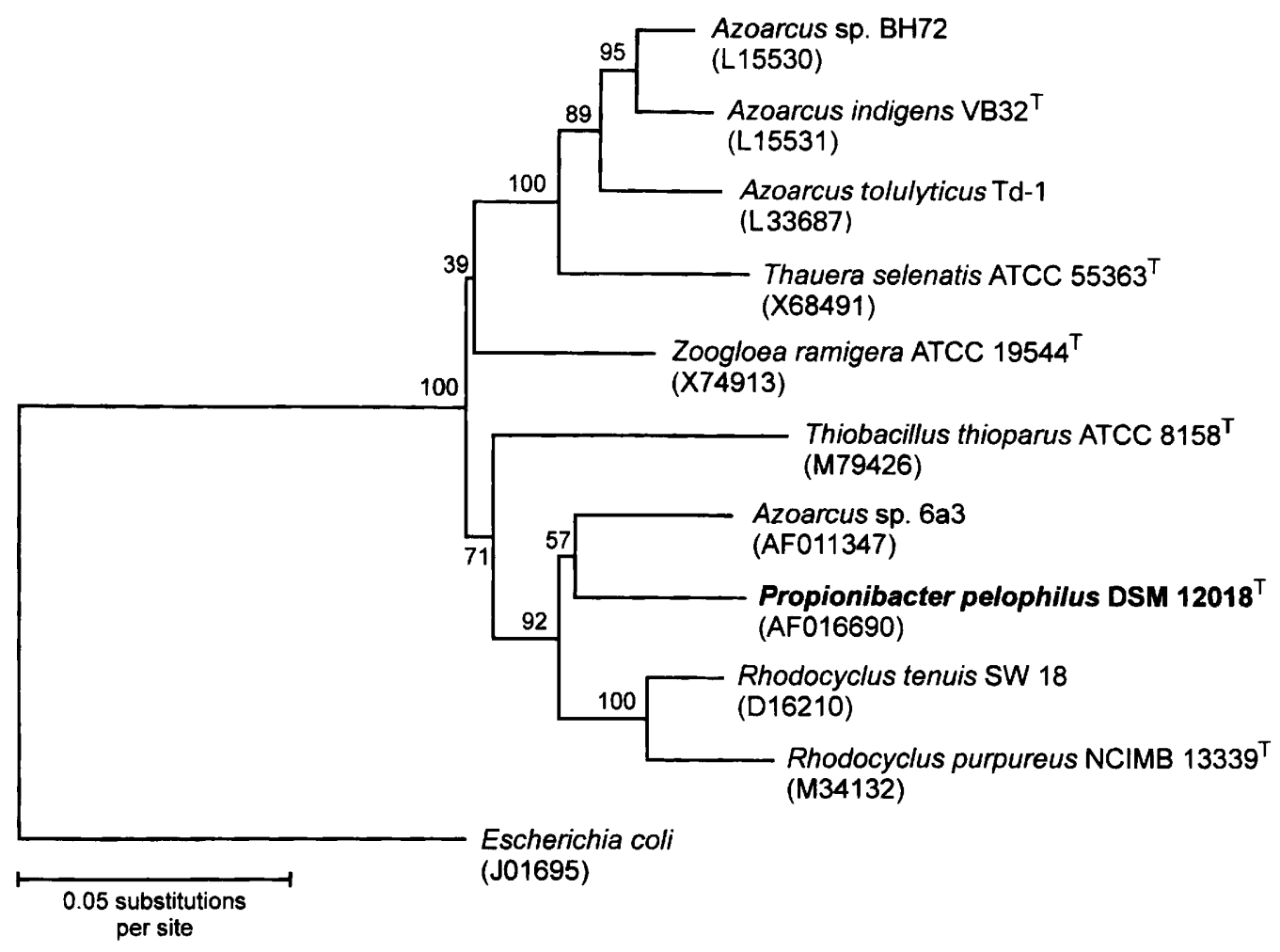

Fig. 2. Phylogenetic relationships of strain asp $66^{\top}$ (Propionibacter pelophilus) with species of the $\beta$-subclass of the Proteobacteria. The phylogenetic tree is based on a distance matrix of 16S rRNA sequences and was constructed using the neighbour-joining method. Escherichia coli was used as an outgroup. Bootstrap values (in percentages) are based on 500 replicates and are given at each internal node. The accession numbers of the sequences of the reference strains are given in parentheses.

position of this strain, the 16S rRNA gene was amplified by PCR and the nucleotide sequence was subsequently determined. Comparison of the nucleotide sequence (1468 bp) of the rRNA gene of Acidaminobacter hydrogenoformans with entries in GenBank showed that it was most similar to $16 \mathrm{~S}$ rRNA genes of species belonging to the low- $\mathrm{G}+\mathrm{C}$ sub-group of the Gram-positive bacteria. The phylogenetic analysis of Acidaminobacter hydrogenoformans consistently ( $100 \%$ bootstraps) placed this bacterium in the phenotypically diverse cluster XI of the Clostridium subphylum (Fig. 1). Acidaminobacter hydrogenoformans displayed only a loose association (sequence similarity levels between 81 and $84 \%$ ) with Eubacterium saphenum, Eubacterium brachy, Eubacterium timidum and 'Clostridium aminobutyricum'and grouped with Clostridium halophilum but with a rather low bootstrap value.

\section{Strain asp $66^{\top}$ belongs to the $\beta$-subclass of the Proteobacteria}

The 16S rRNA gene from strain asp $66^{\mathrm{T}}$ was amplified by PCR and the nucleotide sequence of the PCR product was determined directly. The sequence consisted of 1485 nucleotides, which is approximately $97 \%$ of the complete $16 \mathrm{~S}$ rRNA gene. A comparison of the asp $66^{\mathrm{T}} \mathrm{rRNA}$ gene with entries in GenBank showed that this gene was highly similar to $16 \mathrm{~S}$ rRNA genes of bacteria belonging to the $\beta$-subclass of the Proteobacteria, in particular to Rhodocyclus tenuis (94\% similarity), Rhodocyclus purpureus (93\% similarity) and Azoarcus sp. strain 6a3 (94.5\% similarity). This was confirmed by a phylogenetic analysis in which asp $66^{\mathrm{T}}$ consistently clustered with the Rhodocyclus species (Fig. 2, 100\% bootstraps). A maximum-parsimony analysis using DNAPARS resulted in one most-parsimonious tree with the same topology as the distance tree shown in Fig. 2.

\section{DISCUSSION}

A phylogenetic analysis of Acidaminobacter hydrogenoformans based on the nucleotide sequence of the 16S rRNA gene showed it to be a member of the Clostridium subphylum of the Gram-positive bacteria. This grouping with Gram-positives is in agreement with electron micrographs of the cell wall in which an outer membrane was not visible (Stams \& Hansen, 1984). Acidaminobacter hydrogenoformans displays some similarities with Eubacterium acidaminophilum (Zindel et al., 1988). Both organisms are strict anaerobes that can grow on glycine and on serine in pure culture and utilize more amino acids such as 
Table 1. Comparison of Pelobacter propionicus with other important bacteria with a propionic fermentation and with its phylogenetic neighbours

\begin{tabular}{|c|c|c|c|c|c|c|}
\hline Organism(s) & Phylogenetic group & $\begin{array}{c}\text { Sugars } \\
\text { fermented }\end{array}$ & Oxygen tolerance & $\mathbf{N}_{2}$ fixation & $\begin{array}{l}\text { Dissimilatory } \\
\text { sulfate reduction }\end{array}$ & $\begin{array}{c}\text { Propionic } \\
\text { fermentation }\end{array}$ \\
\hline Propionibacter pelophilus & $\beta$-Proteobacteria & Yes & Rather oxygen-tolerant anaerobe & Yes & No & Yes \\
\hline Pelobacter propionicus & $\delta$-Proteobacteria & No & Obligate anaerobe & Yes & No & Yes \\
\hline Desulfobulbus propionicus & $\delta$-Proteobacteria & No & Obligate anaerobe & Yes & Yes & Yes \\
\hline Propionibacterium & High-G + C Gram-positives & Yes & Oxygen-tolerant anaerobe & No & No & Yes \\
\hline Rhodocyclus tenuis & $\beta$-Proteobacteria & No & $\begin{array}{l}\text { Anoxygenic phototroph, facultative } \\
\text { anaerobe }\end{array}$ & Yes & No & No \\
\hline Azoarcus & $\beta$-Proteobacteria & No & Aerobe or facultative anaerobe & Yes (most strains) & No & No \\
\hline
\end{tabular}

alanine and leucine when grown in co-culture with a hydrogen and formate-utilizing methanogen or Desulfovibrio strain. The substrate spectrum, however, differs considerably. Eubacterium acidaminophilum also stains Gram-negative but has a Gram-positive cell wall structure. Syntrophic utilization of amino acids (alanine and isoleucine) has also been reported for Clostridium sporogenes, an organism that in pure culture can dispose of reducing equivalents in a Stickland reaction (Wildenauer \& Winter, 1986; Winter et al., 1987). C. sporogenes is a member of cluster I of the Clostridium subphylum (Collins et al., 1994). Cluster XI is only distantly related to the true clostridia of cluster I and according to Collins et al. (1994) will comprise a number of new genera after a complete revision of the genus Clostridium. In the phylogenetic tree of Fig. 1 strain glu 65 grouped with Clostridium halophilum, an organism with a $\mathrm{G}+\mathrm{C}$ content of over $20 \mathrm{~mol} \%$ lower than strain glu 65 ; this species utilizes a number of amino acids in a Stickland reaction with betaine and also ferments several sugars (Fendrich et al., 1990). The phylogenetic position of glu 65 in cluster XI is such that it clearly constitutes a separate genus and its status as the type strain of Acidaminobacter hydrogenoformans therefore requires no changes.

Strain asp $66^{\mathrm{T}}$ belongs to the $\beta$-subclass of the Proteobacteria with isolate $6 \mathrm{a} 3$ of Reinhold-Hurek et al. (1993) and $R$. tenuis as its closest relatives (94.5 and $94 \%$ similarity in $16 \mathrm{~S}$ rRNA gene sequence, respectively). Strain $6 \mathrm{a} 3$ belongs to Azoarcus cluster D. The genus Azoarcus is known to consist of a number of phylogenetically distantly related clusters (Hurek et al., 1997) of nitrogen-fixing organisms with a respiratory metabolism. R. tenuis is an anoxygenic phototroph; it utilizes a wide variety of substrates, can fix $\mathrm{N}_{2}$ and in the dark it can grow with oxygen as electron acceptor (Trüper \& Imhoff, 1992). The phylogenetic and phenotypic differences with related taxa (Table 1) indicate that strain asp $66^{\mathrm{T}}$ belongs to a new genus and species for which we propose the name Propionibacter pelophilus. The description (see below) is based on data from the present study and from Hansen et al. (1990).

Propionibacter pelophilus is the first representative of the $\beta$-subclass of the Proteobacteria with a propionic fermentation. A propionic fermentation is carried out by a wide variety of bacteria belonging to various phylogenetic groups. Examples are the high-G+C Gram-positive genus Propionibacterium (Olsen et al., 1994), some representatives of the Clostridium subphylum (see Tholozan et al., 1992; Evers et al., 1993; Collins et al., 1994, for example), certain rod-shaped species of the $\delta$-subclass of the Proteobacteria (Schink, 1984), coccoid and curved bacteria which belong to cluster IX of the Gram-positive anaerobes such as Veillonella, Selenomonas and Pectinatus (Collins et al., 1994; Willems \& Collins, 1995), and Gram-negative vibrioid or spirilloid bacteria of unknown phylogenetic position such as Anaerovibrio (Prins, 1984) and Propionispira (Schink et al., 1982). A propionic fermentation with succinate as an additional product was recently reported for oxygen-tolerant saccharolytic ultramicrobacteria from rice paddy soil belonging to the Verrucomicrobiales (Janssen et al., 1997). Among the Proteobacteria, bacteria that can carry out a propionic fermentation have been found in two genera of the $\delta$-subclass, Pelobacter and Desulfobulbus. Desulfobulbus propionicus is a rod-shaped, sulfatereducing bacterium which, in the absence of sulfate, ferments some substrates (lactate, pyruvate and ethanol) to acetate and propionate via a succinate pathway that involves transcarboxylase (Stams et al., 1984). The strict anaerobe Pelobacter propionicus carries out a propionic fermentation with only a few substrates not including sugars. Despite similarities such as the ability to fix $\mathrm{N}_{2}$, the propionic fermentation, cellular morphology and only a small difference in the $\mathrm{G}+\mathrm{C}$ content of the DNA, Propionibacter pelophilus and Pelobacter propionicus appear to belong to different phylogenetic sub-groups (Evers et al., 1993; Schink, 1984).

\section{Description of Propionibacter gen. nov.}

Propionibacter (Pro.pioni.ba'c.ter. M.L. n. acidum propionicum propionic acid; M.L. masc. n. bacter equivalent of Gr. neut. n. bakterion small rod; M.L. masc. n. Propionibacter propionic acid rod).

Gram-negative rod-shaped cells that may be motile by one polar flagellum. Multiplying by binary fission. No spores formed. Anaerobic to aerotolerant metabolism. In the absence of nitrate substrates are fermented with 
propionate and acetate as characteristic products. Growth is supported by simple organic compounds such as sugars, dicarboxylic acids, sugar alcohols and aspartate. Nitrate reduced to nitrite. Does not use sulfate as electron acceptor. Can utilize molecular nitrogen as nitrogen source. The genus belongs to the $\beta$-subclass of the Proteobacteria. Type species Propionibacter pelophilus.

\section{Description of Propionibacter pelophilus sp. nov.}

Propionibacter pelophilus (pe.lo'phi.lus. Gr. n. pelos mud; Gr. adj. philus loving; M.L. adj. pelophilus mudloving).

Cells are rod-shaped $(0 \cdot 9-1 \cdot 1 \mu \mathrm{m}$ long and $0 \cdot 5-0 \cdot 6 \mu \mathrm{m}$ wide). Gram-negative cell envelope ultrastructure with an outer membrane. Cells may be motile by means of one polar flagellum. Colonies on anaerobic plates with aspartate as substrate are slimy white. Grows in mineral media with a single fermentable substrate. Uses the following energy substrates: L-aspartate, fumarate, L-malate, pyruvate, oxaloacetate, citrate, fructose, glucose, xylose, gluconate, arabitol, xylitol, mannitol, arabinose and mannose. Does not ferment glycine, L-alanine, L-serine, L-threonine, L-methionine, L-glutamate, L-histidine, L-arginine, L-lysine, lactate, $\alpha$-ketoglutarate, glycolate, succinate, propionate, butyrate, glycerol, ethanol, propanol, 2,3-butanediol, acetoin, cellulose, cellobiose, lactose, sucrose, maltose, melibiose, starch, sorbose, rhamnose, galactose, sorbitol, pectin, peptone, xylan or inulin. Indole-negative, urease-negative; does not liquefy gelatin. Growth on glucose and aspartate possible at initial $\mathrm{pH}$ of $6 \cdot 5-8.5$, the optimum being around 7.5-8.0. Final $\mathrm{pH}$ of glucose-fermenting cultures is $5 \cdot 5$. Temperature optimum $27-30^{\circ} \mathrm{C}$; no growth at $35^{\circ} \mathrm{C}$. Sulfate can be used as sulfur source but growth in the absence of sulfide leads to cell clumps. Best growth under anoxic conditions in sulfide-reduced media but growth is possible in stationary cultures under air. No growth in well-aerated cultures. $\mathrm{G}+\mathrm{C}$ content of the DNA is $60.8 \mathrm{~mol} \%$. Habitat: anoxic freshwater and estuarine sediments. Type strain: strain asp $66^{\mathrm{T}}(=\mathrm{DSM}$ $\left.12018^{\mathrm{T}}\right)$.

\section{ACKNOWLEDGEMENTS}

We thank Peter Terpstra for excellent technical assistance.

\section{REFERENCES}

Altschul, S. F., Gish, W., Miller, W., Muers, E. W. \& Lipman, D. J. (1990). Basic local alignment search tool. J Mol Biol 215, 403-410.

Collins, M. D., Lawson, P. A., Willems, A., Cordoba, J. J., Fernandez-Garayzubal, J., Garcia, P., Cai, J., Hippe, H. \& Farrow, J. A. E. (1994). The phylogeny of the genus Clostridium: proposal of five new genera and eleven new species combinations. Int $J$ Syst Bacteriol 44, 812-826.

Evers, S., Weizenegger, M., Ludwig, B. \& Schleifer, K. H. (1993).
The phylogenetic positions of Pelobacter acetylenicus and Pelobacter propionicus. Syst Appl Microbiol 16, 216-218.

Felstenstein, J. (1995). Confidence limits on phylogenies: an approach using the bootstrap. Evolution 39, 783-791.

Fendrich, C., Hippe, H. \& Gottschalk, G. (1990). Clostridium halophilum sp. nov. and $C$. litorale sp. nov., an obligate halophilic and a marine species degrading betaine in a Stickland reaction. Arch Microbiol 154, 127-132.

Hansen, T. A., Nienhuis-Kuiper, H. E. \& Stams, A. J. M. (1990). A rod-shaped, gram-negative, propionigenic bacterium with a wide substrate range and the ability to fix molecular nitrogen. Arch Microbiol 155, 42-45.

Hurek, T., Wagner, B. \& Reinhold-Hurek, B. (1997). Identification of $\mathrm{N}_{2}$-fixing plant- and fungus-associated Azoarcus species by PCR-based genomic fingerprints. Appl Environ Microbiol 63, 4331-4339.

Janssen, P. H., Schumann, A., Mörschel, E. \& Rainey, F. A. (1997). Novel anaerobic ultramicrobacteria belonging to the Verrucomicrobiales lineage of bacterial descent isolated by dilution culture from anoxic rice paddy soil. Appl Environ Microbiol 63, 1382-1388.

Kimura, M. (1980). A simple model for estimating evolutionary rates of base substitutions through comparative studies of nucleotides sequences. $J$ Mol Evol 16, 111-120.

Olsen, G. J., Woese, C. R. \& Overbeek, R. (1994). The winds of (evolutionary) change: breathing new life into microbiology. $J$ Bacteriol 176, 1-6.

Prins, R. A. (1984). Genus X. Anaerovibrio Hungate $1966,80^{\mathrm{AL}}$, pp. 653-655. In Bergey's Manual of Systematic Bacteriology, vol. 1, pp. 653-655. Edited by N. R. Krieg \& J. G. Holt. Baltimore: Williams \& Wilkins.

Reinhold-Hurek, B., Hurek, T., Gillis, M., Hoste, B., Vancanneyt, M., Kesters, K. \& De Ley, J. (1993). Azoarcus gen. nov., nitrogenfixing proteobacteria associated with roots of kallar grass (Leptochloa fusca (L.) Kunth), and description of two species, Azoarcus indigens sp. nov. and Azoarcus communis sp.nov. Int $J$ Syst Bacteriol 43, 574-584.

Saitou, N. \& Nei, M. (1987). The neighbor-joining method: a new method for reconstructing phylogenetic trees. Mol Biol Evol 4, 406-425.

Schink, B. (1984). Fermentation of 2,3-butanediol by Pelobacter carbinolicus sp. nov. and Pelobacter propionicus sp. nov., and evidence for propionate formation from $\mathrm{C}_{2}$ compounds. $\mathrm{Arch}$ Microbiol 137, 33-41.

Schink, B., Thompson, T. E. \& Zeikus, J. G. (1982). Characterization of Propionispira arboris gen. nov. sp. nov., a nitrogenfixing anaerobe common to wetwoods of living trees. $J$ Gen Microbiol 128, 2771-2779.

Stams, A. J. M. \& Hansen, T. A. (1984). Fermentation of glutamate and other compounds by Acidaminobacter hydrogenoformans gen. nov. sp. nov., an obligate anaerobe isolated from black mud. Studies with pure cultures and mixed cultures with sulfate-reducing and methanogenic bacteria. Arch Microbiol 137, 329-337.

Stams, A. J. M., Kremer, D. R., Nicolay, K., Weenk, G. H. \& Hansen, T. A. (1984). Pathway of propionate formation in Desulfobulbus propionicus. Arch Microbiol 139, 167-173.

Tholozan, J. L., Touzel, J. P., Samain, E., Grivet, J. P., Prensier, G. \& Albagnac, G. (1992). Clostridium neopropionicum sp. nov., a strict anaerobic bacterium fermenting ethanol to propionate through acrylate pathway. Arch Microbiol 157, 249-257.

Trüper, H. G. \& Imhoff, J. F. (1992). The genera Rhodocyclus and 
Rubrivivax. In The Prokaryotes, pp. 2556-2561. Edited by A. Balows, H. G. Trüper, M. Dworkin, W. Harder \& K. H. Schleifer. New York: Springer.

Van de Peer, Y. \& De Wachter, R. (1995). TREECON for Windows: a software package for the construction and drawing of evolutionary trees for the Microsoft Windows environment. Comput Appl Biosci 10, 569-570.

Van der Maarel, M. J. E. C., Jansen, M., Haanstra, R., Meijer, W. G. \& Hansen, T. A. (1996). Demethylation of dimethylsulfoniopropionate to 3-S-methylmercaptopropionate by marine sulfate-reducing bacteria. Appl Environ Microbiol 62, 3978-3984.

Wildenauer, F. X. \& Winter, J. (1986). Fermentation of isoleucine and arginine by pure and syntrophic cultures of Clostridium sporogenes. FEMS Microbiol Ecol 38, 373-379.

Willems, A. \& Collins, M. D. (1995). Phylogenetic placement of Dialister pneumosintes (formerly Bacteroides pneumosintes) within the Sporomusa subbranch of the Clostridium subphylum of the gram-positive bacteria. Int J Syst Bacteriol 45, 403-405.

Winter, J., Schindler, F. \& Wildenauer, F. X. (1987). Fermentation of alanine and glycine by pure and syntrophic cultures of Clostridium sporogenes. FEMS Microbiol Ecol 45, 153-161.

Zindel, U., Freudenberg, W., Rieth, M., Andreesen, J. R., Schnell, J. \& Widdel, F. (1988). Eubacterium acidaminophilum sp. nov., a versatile amino acid-degrading anaerobe producing or utilizing $\mathrm{H}_{2}$ or formate. Arch Microbiol 150, 254-266. 